\title{
An insight into the reproductive biology of the bearded goby Sufflogobius bibarbatus
}

\author{
A. C. Utne-Palm, L. Locatello, I. Mayer, M. J. Gibbons and M. B. Rasotto
}

\begin{abstract}
Preliminary results obtained from histological analyses of the male reproductive organs, supplemented with field and behavioural data, indicate that Sufflogobius bibarbatus, a small, slow growing gobiid exhibiting low fecundity, which plays an important role in the food web off Namibia, where large areas of the shelf are hypoxic, spawns demersally. Large males defend benthic nests, possibly at the edge of the hypoxic shelf. Male reproductive strategy appears to be flexible, and tentative evidence to suggest that polygyny and sneaking may also occur is presented.
\end{abstract}

The Namibian shelf is dominated by organic-rich mud where intense decay processes create a surface sediment with high concentrations of hydrogen sulphide and methane (Lavik et al ., 2009). Hypoxic conditions ( $<1 \mu \mathrm{M}$ dissolved oxygen) cover $>50 \%$ of the shelf area (Lavik et al., 2009).

The goby Sufflogobius bibarbatus (von Bonde 1923) occurs across the shelf off southwest Africa, and is found from Angola to South Africa, being most common off central Namibia (Cruickshank et al ., 1980). Sufflogobius bibarbatus is a slow growing species (13 cm standard length at 6 years) with late sexual maturation ( $2-3$ years) and low fecundity (Melo \& le Clus, 2005). Despite its low productivity and the hostile environment it inhabits, it is very successful in the region and has assumed a central position as a key prey in the food web following the collapse of sardines Sardinops sagax (Jenyns 1842) (Cury \& Shannon, 2004). The success of S. bibarbatus can be attributed to a suite of unusual dietary, behavioural and physiological adaptations: adults shuttle between the hypoxic bottom waters to hide and feed during daylight and the more oxygenated pelagos to digest and re-oxygenate during darkness (Utne-Palm et al ., 2010). Although the larvae of $S$. bibarbatus can be found in the water column for much of the year, they peak in abundance during the austral summer and are least common in winter (O’Toole, 1978). Their eggs have never been recovered from plankton samples, suggesting that, despite the harsh conditions on the seafloor, this species might be a demersal spawner, as are most gobies (Miller, 1984). It is likely therefore that males build and defend nests and care for the eggs.

Males of demersal spawning gobies often lay sperm-containing mucous trails in their nests before and during spawning, which slowly dissolve and release active sperm for 
several hours (Mazzoldi et al ., 2011). Seminal fluid mucins are produced by paired accessory sperm duct glands (SDGs) whose size and secretory activity vary in species where males perform alternative mating tactics (Mazzoldi et al ., 2011). In some gobies, in addition to large-sized and territory-holding males, there are also smaller, so called sneakers, which steal fertilizations from the territorial ones (Taborsky, 2008). Territorial males, which build nests and perform parental care, exhibit larger SDGs and more abundant secretions than sneaker ones (Mazzoldi et al ., 2011). Of the two male mating tactics, sneaking is less energetically costly and, although it has yet to be demonstrated, it might be expected that sneaking would be more prevalent under conditions of hypoxia.

Hypoxia has a negative impact on fish reproduction through, e.g . its impact on metabolism (Jobling, 1994) and endocrine disruption (Thomas et al ., 2007), as well as changing reproductive behaviour and mating tactics. Confronted with low oxygen water, male sand gobies Pomatoschistus minutus (Pallas 1770) build nests with larger openings (Lissåker et al ., 2003), whilst the male dwarf Victoria mouthbrooder Pseudocrenilabrus multicolor victoriae (Seegers 1990), may reduce the total number of displays compared to males acclimated to high oxygen conditions (Gotanda et al ., 2011).

Here, the testes and SDGs of $S$. bibarbatus collected off Namibia were exam- ined histologically, supplemented with behavioural observations in the laboratory, in order to evaluate both the occurrence of demersal spawning and the possibility of alternative male mating tactics.

Sufflogobius bibarbatus were collected during a cross-shelf cruise conducted in April (austral autumn) 2008 off Walvis Bay between $23^{\circ} 30^{1} \mathrm{~S} ; 13^{\circ} 40^{1} \mathrm{E}$ and $23^{\circ} 16^{1} \mathrm{~S} ; 14^{\circ} 23^{1}$ E. Sufflogobius bibarbatus were caught by demersal and pelagic trawls. Trawls were taken during day and night, catching $S$. bibarbatus both when in the pelagos and on the seabed. The physical and chemical environment were monitored using a Sea-Bird SBE 19 conductivity, temperature and depth sensor (CTD), fitted with an SBE 43 oxygen probe (www.seabird.com).

A maximum of 100 random $S$. bibarbatus specimens were measured (total length, $L \mathrm{~T}$, $\pm 1 \cdot 0 \mathrm{~mm}$ ) from each trawl, while the sex ratio was determined from further random sub-samples. Sex was determined from the shape of the genital papilla or by dissection and visual inspection of the gonads. Following dissection, mature testes and SDGs were excised and preserved in 4\% neutral buffered formaldehyde solu- tion, before being weighed ( $M$ TEST and $M$ SDG) to determine the gonado-somatic index ( $I \mathrm{G}$ ) from $I_{\mathrm{G}}=100 M$ TEST $M \mathrm{~T}^{-1}$ and the SDG somatic index ( $\left.I \mathrm{SDG}\right)$ from $I \mathrm{SDG}=100$ $M$ SDG $M \mathrm{~T}^{-1}(n=50)$. Total mass $(M \mathrm{~T})$ and not gutted mass was used, as gut and gut contents represent on average only $12 \%$ of $M$ (95\% c.i., $11-14 \%, n=274$ ) in fish between 62 and $123 \mathrm{~mm} L \mathrm{~T}$ and SDGs of 25 males between 89 and $147 \mathrm{~mm} \mathrm{LT}$ were then embedded in paraplast, serially sectioned transversely, and mounted on slides for histological examina- tion. Sections were first stained with haematoxylin and eosin; polysaccharides were detected using the reaction of periodic acid-Schiff; sulphated and 
non-sulphated mucins by the alcian blue method at $\mathrm{pH} 1 \cdot 0$ and $2 \cdot 5$, respectively; and proteins were stained using the mercury bromophenol blue method (Pearse, 1985).

The cross-shelf CTD transect revealed a hypoxic zone extending between 20 and $60 \mathrm{~m}$ above the seabed. In this zone, oxygen levels dropped from 10 to $<2 \%$ oxygen saturation at the bottom [Utne-Palm et al . (2010), Supplementary information Figs S1 and S2]. On the hypoxic shelf $(60-150 \mathrm{~m}$ depth) $S$. bibarbatus between 70 and $90 \mathrm{~mm} L \mathrm{~T}$ dominated the population: significantly smaller individuals were recorded in the pelagos $(80.04 \pm 9.54 \mathrm{~mm}$, mean \pm s.d.) than epibenthos $(88.87 \pm 5.79 \mathrm{~mm})$ ( $t$-test, $t=7.69, P<$ $0 \cdot 001)$. At the deeper (180 - $200 \mathrm{~m}$ depth) and more oxy- genated shelf edge (>7\% oxygen saturation), there was a bimodal size distribution with smaller juveniles (45.33 \pm $10.55 \mathrm{~mm})$ dominating the pelagos and larger adults $(98.69 \pm 18.45 \mathrm{~mm})$ dominating the epibenthos ( $t$-test, $t=50 \cdot 17, P<0 \cdot 001)$.

Visual inspection of dissected gonads indicated that those of immature fish $(<60 \mathrm{~mm}$ $L \mathrm{~T}$ ) were transparent, thin and string-like, while maturing ( $>60 \mathrm{~mm} L \mathrm{~T}$ ) males were enlarged and increasingly white in colour. Mature males ( $>88 \mathrm{~mm} \mathrm{LT}$ ) and mature females were found exclusively at the outer, more oxygenated shelf edge, whilst maturing specimens of both sexes inhabited the more hypoxic shelf. The M:F was $1 \cdot 35$ over the shelf (0.9, pelagos; $1 \cdot 8$, epibenthos) and 1.2 in the epibenthos at the shelf edge (all pelagic caught fish here were juveniles).

Larger males had significantly larger testes $\left(F_{1,43}=4 \cdot 445, P<0 \cdot 05, r^{2}=0 \cdot 094\right)$ [Fig. 1(a)] and SDGs $\left(F_{1,43}=14 \cdot 29, P<0 \cdot 001, r^{2}=0 \cdot 249\right)$ [Fig. 1(b)] than smaller males. All 25 males whose reproductive organs were histologically examined were sexually mature with paired testes, suspended from the dorsal wall of the coelomic cavity by a mesorchium. The sperm transport system consisted of two main sperm ducts, fusing into a common duct from which, before reaching the urogenital opening, a pair of solid, wing-like accessory structures grew out. Testes were organized into lobules, of the unrestricted spermatogonial type (Grier, 1981), whose walls were lined with germinal epithelium, presenting all the different stages of spermatogenesis: lumina full of sperm were observed in ripe males [Fig. 2(a), (b)]. The SDGs were multi-chambered, as commonly observed in gobies (Mazzoldi et al ., 2011). The chamber wall consisted of an internal single layer of epithelial cells, a basal lamina and a thin external layer of connective tissue [Fig. 2(c)]. The chamber lumen did not contain sperm but was filled with a substance that reacted positively to sialoglycoproteins [Fig. 2(d), (e)], which have been noted as the dominant component of seminal fluid in other demersal spawning gobies (Mazzoldi et al., 2011).

The morphology of the male reproductive tract, and the generally positive rela- tionship between male size and both $I \mathrm{G}$ and $I$ SDG suggests that, like other gobies (Breder \& Rosen, 1966), S. bibarbatus is a demersal spawner. It also probably builds nests that it defends. SDG size is influenced by nest type and environment (Maz- zoldi et al ., 2005). Given that $S$. bibarbatus seems to prefer muddy, over sandy, substrata (Salvanes et al., 2011), it is also possible that the very large quantities of mucus secreted could be used to compact nest walls or to minimize bacterial infections, as observed for other gobies 
(Mazzoldi et al ., 2011). Evidence of territoriality between male S. bibarbatus was obtained from laboratory observations on pairs of large (92-102 $\mathrm{mm} L \mathrm{~T}$ ) healthy fish collected at the shelf edge. These males were kept in well-aerated, flow-through aquaria $(100 \mathrm{~cm} \times 100 \mathrm{~cm} \times 40 \mathrm{~cm})$, and it was noted that the larger individual attacked the smaller, and displayed territorial behaviour (attacking, biting, chasing, erecting fins and inflating mouth).
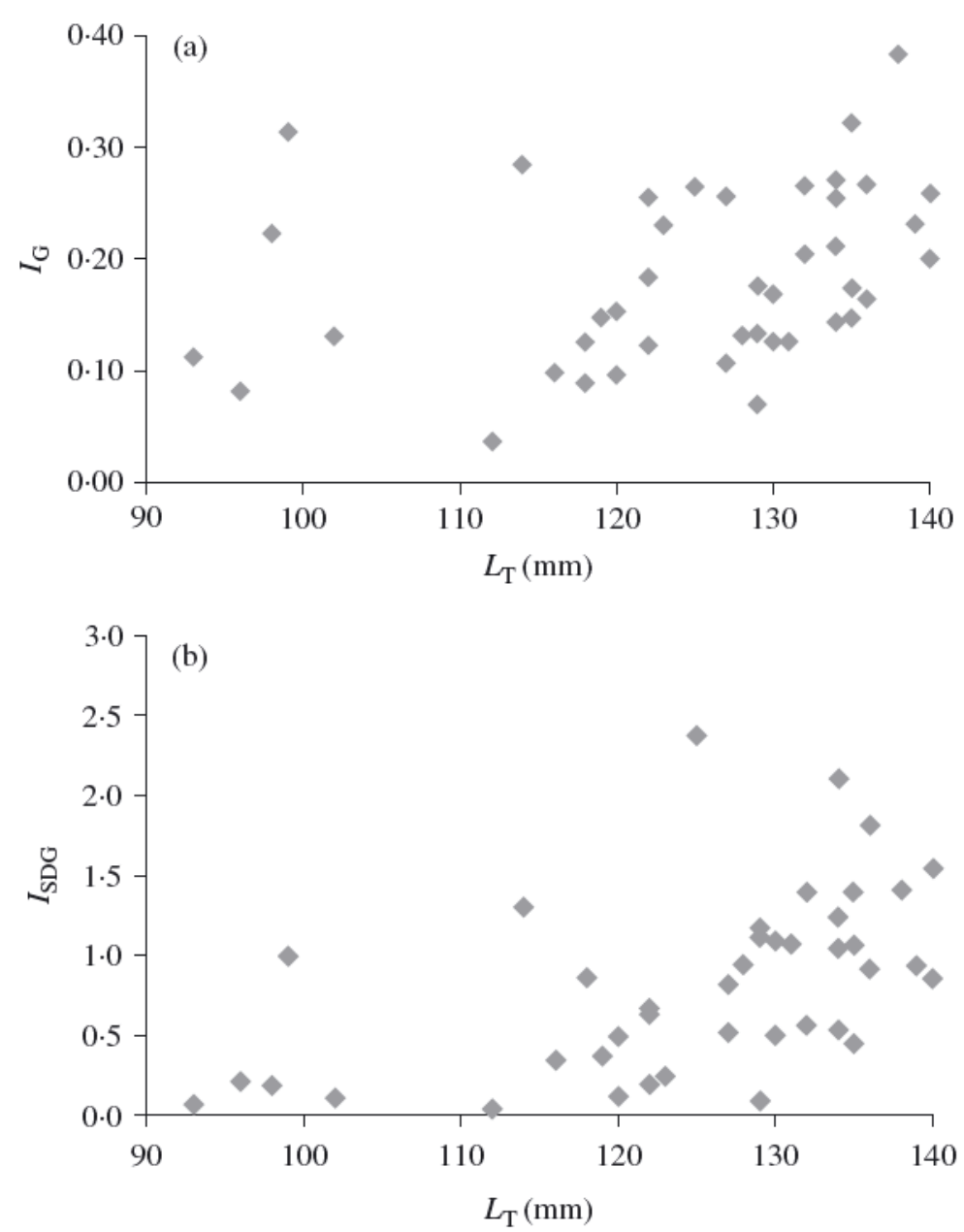

FIG. 1. Relationship between (a) gonado-somatic index $\left(I_{\mathrm{G}}\right)$ and (b) sperm duct gland index $\left(I_{\mathrm{SDG}}\right)$ and male total length $\left(L_{\mathrm{T}}\right)(n=50)$ of Sufflogobius bibarbatus. $\diamond$, individual measurements.

Whilst larger males generally had larger SDGs than smaller males, some of the latter had comparatively large testes and small, sperm-free SDGs (Fig. 1). This suggests that some males may be, or may have been, sneakers, although the small sample size precludes firm conclusions. In some other gobies, males may change their reproductive strategy depending on social context, i.e. male competition and female availability (Immler et al., 2004; Scaggiante et al., 2004).

The SDGs of $S$. bibarbatus are four times heavier than the testes, and this ratio is much higher than observed in territorial males of most other gobies, which generally invest equally in both gonads and accessory organs (Mazzoldi et al ., 2005). This extraordinary investment in SDGs can also be interpreted in terms of polygyny, the levels of which are known to influence SDG development (Mazzoldi et al ., 2005). Preliminary observations on $S$. bibarbatus spawning behaviour in captivity showed that a single male 
mated and cared for the eggs that were released by three females (A. Kotze, H. Skrypzeck \& B. Currie, unpubl. data).

To what extent either sneaking or polygyny are prevalent in field populations of $S$. bibarbatus is presently unknown, and only a slightly male biased $\mathrm{M}: \mathrm{F}=1$

(a)

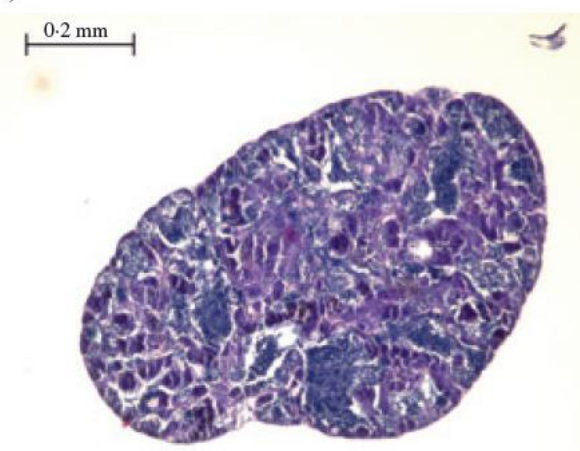

(c)

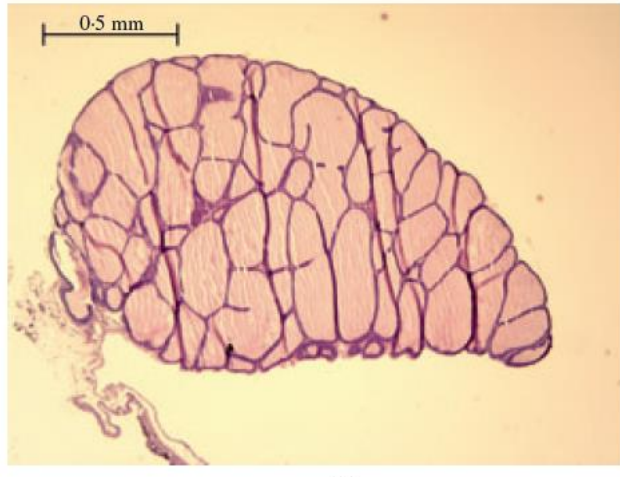

(b)

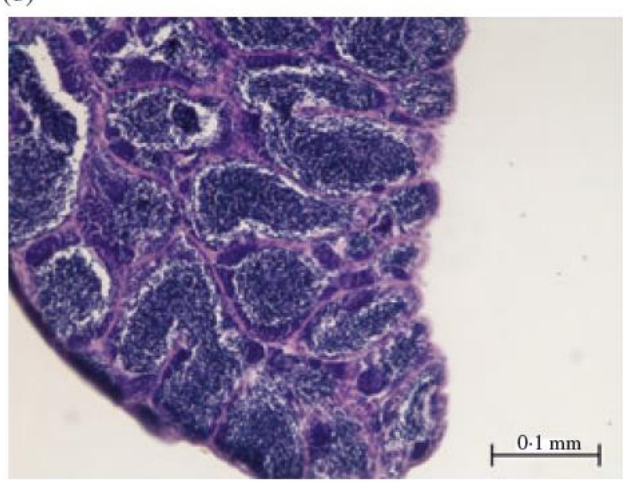

(d)

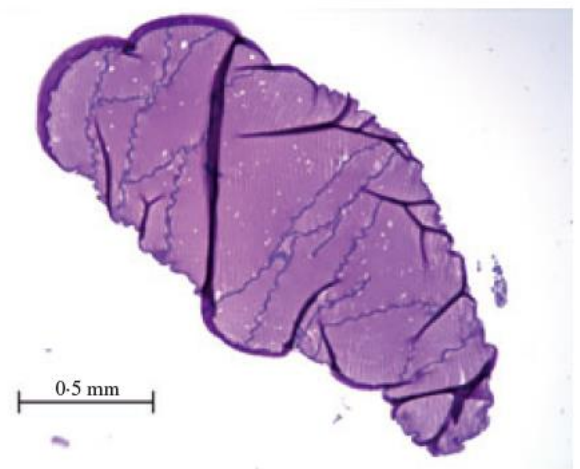

(e)

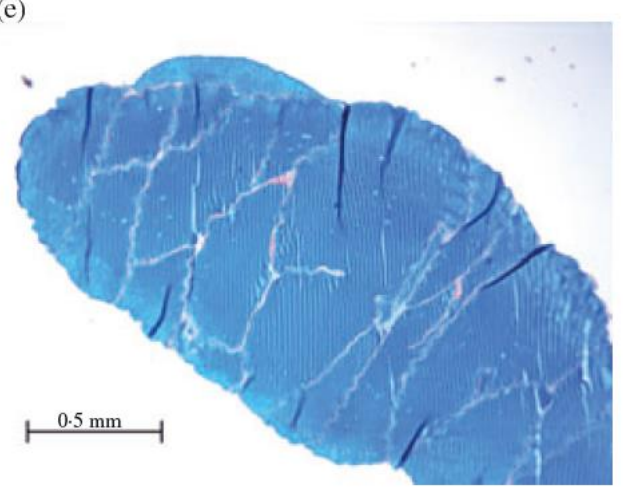

FIG. 2. Cross sections of sperm duct gland (SDG) and testis of male Sufflogobius bibarbatus. Cross-sections of (a) whole testis, (b) part of testis showing spermatogonia and cysts of spermatocytes; secondary spermatocytes and spermatids are present in the lobule walls, while sperm fill the lobule lumina. Haematoxylin and eosin. (c) SDG of a $98 \mathrm{~mm} L_{\mathrm{T}}$ male. Chambers are highly extended and their lumina filled with secretion. Haematoxylin and eosin. (d) SDG of a $140 \mathrm{~mm} L_{\mathrm{T}}$ male. Chambers are highly extended and their lumina filled with secretion. Both epithelial cells and secretion react positively to periodic acidSchiff (PAS) staining. (e) SDG of a $140 \mathrm{~mm} L_{\mathrm{T}}$ male. Chambers are highly extended and their lumina filled with secretion. Secretion reacts positively to alcian blue-PAS (pH 2.5).

Although a male biased sex ratio was observed over the hypoxic shelf, it should be remembered that males in this region were smaller than those at the shelf-edge and were maturing, not mature. Sex ratio can, however, vary in time and space due to both biotic and abiotic factors (Forsgren et al ., 2004; Baroiller et al ., 2009), and given that the present observations were made at the end of the active spawning season, it is likely 
that it would change through time with, e.g . changes in hypoxia and sulphide levels (Thomas et al ., 2007). As a consequence, it is likely that a male's choice of reproductive tactic would similarly change through the year. Also presence of males in the catches can decrease during the reproductive season, particularly if a nest burrowing and tending activity is present.

Perhaps unsurprisingly, it seems that $S$. bibarbatus spawns and rears its eggs in the more oxygen-rich waters located towards the edge of the shelf off Namibia. Benthic spawning in a species with low fecundity occurring in an upwelling area such as the Benguela is more advantageous than pelagic spawning as larvae are less likely to be lost from the system by Ekman transport (Stenevik et al ., 2007). In other words, benthic spawning might help to retain recruitment over the shelf, because whilst larvae have been observed across its width, highest concentrations occur at shallow depths where food is most abundant (O'Toole, 1978). The flexibility in the mating tactics of S. bibarbatus hinted at by the present observations (territoriality, sneaking and polygyny) are in line with its behavioural and trophic flexibilities, and its extraordinary physiology (UtnePalm et al ., 2010), and help towards a better understanding of its unlikely success in such a hostile system over recent time. That said, clearly more work on this intriguing species is still needed.

We wish to thank the Stazione Idrobiologica, Chioggia, University of Padova for letting us to use their laboratories and for providing expert advice. We thank the crew of the R.V. G.O. Sars for their assistance in the fish capture, as well as R. Amundsen and M. Hundt for helping with the onboard fish dissections. We are grateful to A. Kotze, H. Skrypzeck \& B. Currie for sharing their behavioural observations with us. We also thank the two anonymous reviewers whose comments helped to strengthen the text and focus our ideas. The National Research Foundation of South African, the Norwegian Research Council and the Meltzer Fund (Bergen University) provided financial support. 


\section{References}

Baroiller, J. F., D'Cotta, H. \& Saillant, E. (2009). Environmental effects on fish sex determi- nation and differentiation. Sexual Development 3, 118-135.

Breder, C. M. \& Rosen, D. E. (1966). Modes of Reproduction in Fishes. Neptune City, NJ: T.F.H. Publications.

Cedras, R. B., Salvanes, A. G. V. \& Gibbons, M. J. (2011). Investigations into the diet and feeding ecology of the bearded goby, Sufflogobius bibarbatus, off Namibia. South African Journal of Marine Science 33, 313-320.

Cruickshank, R. A., Cooper, J. \& Hampton, I. (1980). Extension to the geographical distribu- tion of pelagic goby Sufflogobius bibarbatus off South West Africa and some mensural and energetic information. Fisheries Bulletin of South Africa 13, 77-82.

Cury, P. \& Shannon, L. (2004). Regime shifts in upwelling ecosystems: observed changes and possible mechanisms in the northern and southern Benguela. Progress in Oceanography 60, 223-243.

Forsgren, E., Amundsen, T., Borg, А̊ . \& Bjelvenmark, J. (2004). Unusually dynamic sex roles in a fish. Nature 429, $551-554$.

Gotanda, K. M., Reardon, E. E. \& Chapman, L. J. (2011). Hypoxia and male behaviour in an African cichlid Pseudocrenilabrus multicolor victoriae. Journal of Fish Biology 78, 2085-2092.

Grier, H. J. (1981). Cellular organization of the testis and spermatogenesis in fishes. American Zoologist 21, 345-357.

Immler, S., Mazzoldi, C. \& Rasotto, M. B. (2004). From sneaker to parental male: change of reproductive traits in the black goby, Gobius niger (Teleostei, Gobiidae). The Journal of Experimental Zoology 301A, 177-185.

Jobling, M. (1994). Fish Bioenergetics. London: Chapman \& Hall.

Lavik, G., Stührmann, T., Brü chert, V., Van der Plas, A., Mohrholz, V., Lam, P., Mußmann, M., Fuchs, B. M., Amann, R., Lass, U. \& Kuypers, M. M. M. (2009). Detoxification of sulphidic African shelf waters by blooming chemolithotrophs. Nature 457, 581-584.

Lisså ker, M., Kvarnemo, C. \& Svensson, O. (2003). Effects of a low oxygen environment on parental effort and filial cannibalism in the male sand goby, Pomatoschistus minutus. Behaviour Ecology 14, 374-381.

Mazzoldi, C., Petersen, C. W. \& Rasotto, M. B. (2005). The influence of mating system on seminal vesicle variability among gobies (Teleostei, Gobiidae). Journal of Zoological Systematics and Evolutionary Research 43, 307-314.

Mazzoldi, C., Patzner, R. \& Rasotto, M. B. (2011). Morphological organization and variability of the reproductive apparatus in gobies. In The Biology of Gobies (Patzner, R., Van Tassell, J. L., Kovacic, M. \& Kapoor, B. J., eds), pp. 367 - 402. Enfield, NH: Science Publishers.

Melo, Y. C. \& Le Clus, F. (2005). Growth and reproduction of the pelagic goby Sufflogobius bibarbatus off the Orange River, southern Africa. African Journal of Marine Science 27, 265-273.

Miller, P. J. (1984). The topology of gobioid fishes. In Fish Reproduction: Strategies and Tactics (Potts, W. \& Wootton, R. J., eds), pp. 119 - 153. London: Academic Press. 
O’Toole, M.J. (1978). Development, distribution and relative abundance of the larvae and early juveniles of the pelagic goby Sufflogobius bibarbatus (von Bonde) off South West Africa 1972-1974. Sea Fisheries Branch Investigation Report, Cape Town. No. 116.

Pearse, A. G. E. (1985). Histochemistry: Theoretical and Applied . London: Churchill Living- stone.

Salvanes, A. G. V., Utne-Palm, A. C., Currie, B. \& Braithwaite, V. A. (2011). Behavioural and physiological adaptations of the bearded goby: a key fish species of the extreme environment of Benguela. Marine Ecology Progress Series 425, 193 202.

Scaggiante, M., Grober, M. S., Lorenzi, V. \& Rasotto, M. B. (2004). Changes along the male reproductive axis in response to social context in a gonochoristic gobiid, Zosterisessor ophiocephalus (Teleostei, Gobiidae), with alternative mating tactics. Hormones and Behavior 46, 607-617.

Stenevik, E. K., Sundby, S. \& Cloete, R. (2007). Diel vertical migration of anchovy Engraulis encrasicolus larvae in the northern Benguela. African Journal of Marine Science 29, 127-136.

Taborsky, M. (2008). Alternative reproductive tactics in fish. In Alternative Reproductive Tactics. An Integrative Approach (Oliveira, R. F., Taborsky, M. \& Brockmann, H. J., eds). Cambridge: Cambridge University Press.

Thomas, T., Rahman, S., Khan, I. A. \& Kummer, J. A. (2007). Widespread endocrine disrup- tion and reproductive impairment in an estuarine fish population exposed to seasonal hypoxia. Proceedings of the Royal Society B 274, 2693-2702.

Utne-Palm, A. C., Salvanes, A. G. V., Currie, B., Kaartvedt, S., Nilsson, G. E., Braithwaite, V., Stecyk, J. A. W., Hundt, M., Flynn, B., van der Bank, M., Peard, K. R., Lunde, I. G., Sandvik, G. K., Klevjer, T. A., Pittman, K., Sweetman, A., Strandabø, R. A. U. (2010). Tropic structure and community stability in an overfished ecosystem. Science 329, 333-336. 